\title{
Mapeamento da dinâmica do uso do solo na bacia hidrográfica Mutum (MT) no período de 1980 a 2010 usando imagens orbitais
}

\author{
Mapping the dynamics of the use of the soil in the river basin Mutum (MT), \\ Brazil, in the period from 1980 to 2010 using orbital images
}

\author{
Pablo André da Silva Vasconcelos ${ }^{\mathrm{a}}$ \\ Jeater Waldemar Maciel Correa Santos ${ }^{b}$ \\ Fabrício Petinelli Aguiar ${ }^{c}$
}

a Bacharelando em Sistemas de Informação na Universidade Federal de Mato Grosso (UFMT), campus de Rondonópolis.

E-mail: pabloandre.vasconcelos@hotmail.com

${ }^{\text {b }}$ Professor orientador graduado em Geografia pela Universidade Estadual de Maringá (UEM), doutor em Geografia Física pela Universidade de São Paulo (USP), com pós-doutorado em

Sensoriamento Remoto/SIG pela Université Rennes II.

E-mail: jeatermaciel@gmail.com

c Bacharelando em Engenharia Agrícola e Ambiental na Universidade Federal de Mato Grosso

(UFTM), campus de Rondonópolis.

E-mail: fabriciopetinelli@gmail.com

Este estudo objetivou analisar as transformações nas paisagens da bacia do rio Mutum, situada no sul de Mato Grosso, por meio do mapeamento do uso e ocupação do solo produzido a partir de imagens Landsat referentes a 1985, 1995, 2005 e 2014. Após sofrerem tratamentos iniciais, foram produzidas composições em falsa cor RGB 5, 4, 3 para a imagem de cada ano. Essas imagens foram interpretadas de modo visual utilizando-se seis classes de uso e ocupação do solo, definidas com base em proposta do Instituto Brasileiro de Geografia e Estatística (2006). Os resultados da classificação permitiram detectar o aumento das áreas de pastagem na bacia em 12\% e agricultura em 6\%; redução das áreas de matas ciliares em 2\%, savana/cerrado em 10\% e da vegetação de áreas úmidas (classe alagamento) em 6\%. Assim, conclui-se que houve significativo incremento das áreas de agricultura e pastagens na bacia no período analisado em detrimento das áreas com vegetação natural (cerrado e matas ciliares) até mesmo em setores sujeitos à inundação sazonal. Esse processo de transformação das paisagens da bacia apresentou sensível redução na década de 2010, provavelmente refletindo influência das políticas internas de governo e flutuações do mercado internacional de grãos e carnes nesse período.

Palavras-chave: bacia do rio Mutum, classificação de imagens, uso e ocupação do solo.

This study aims analyze and quantify the Mutum river watershed landscapes transformations, in Mato Grosso, Brazil, through mapping of land uses and occupation by using Landsat images for the years 1985, 1995, 2005 and 2014. After the initial treatment, that has produced false color RGB 5, 4, 3 compositions for each year image. These results were analyzed by visual mode using six land uses and occupation classes, defined as base of Instituto Brasileiro de Geografia e Estatística (2006) proposal. The classification results allowed detecting the increasing of pastages areas in the watershed in $12 \%$ and agriculture in $6 \%$, and the reduction of areas of the riparian forest in $2 \%$, savannah/cerrado in $10 \%$ and wetland vegetation (overflow classes) in $6 \%$. This way, concludes that has happened a significate increasing in agriculture areas and pastages in the period analyzed over the areas with natural vegetation (riparian forestsand and cerrado) even sector subjected to seasonal flooding. That process of transformation of landscapes in the watershed showed sensible reduction in the decade of 2010, probably reflecting internal policies government influences and fluctuations of the international market of grains and meats in this period.

Keywords: Mutum watershed, classification of images, use and occupation of ground. 


\section{INTRODUÇÃO}

Este estudo refere resultados produzidos no âmbito do projeto Interações dos Processos Socioambientais na Interface do Planalto dos Guimarães com a Planície do Pantanal Mato-grossense (bacia do rio Mutum e baía Sinhá Mariana), que está sendo desenvolvido por pesquisadores do Grupo Agetea (Análise Ambiental, Gestão Territorial e Educação Ambiental), composto por pesquisadores (docentes e discentes) que atuam no Programa de Pós-Graduação em Geografia na Universidade Federal de Mato Grosso (UFMT), campus de Rondonópolis.

A bacia do rio Mutum tem sua área abrangendo tanto terras altas do Planalto dos Guimarães no sudeste do estado de Mato Grosso como "terras baixas" da Planície do Pantanal Mato-grossense, ou seja, situa-se numa zona de transição entre as terras/áreas de produção agrícola comercial das chapadas do Planalto dos Guimarães e as terras/áreas de produção extensiva (ou semiextensiva) de pecuária da Planície do Pantanal.

Além disso, o Pantanal ainda não foi compreendido sob uma abordagem ecológica mais ampla e o avanço dos impactos ambientais sobre essa região, atrelados à carência de informações sobre a biota aquática desse ambiente, reforça a necessidade de maiores investigações acerca dos processos direcionadores do funcionamento dos ecossistemas.

Apesar de os sistemas de produção agrícola comercial (soja, milho, arroz, algodão etc.) da "chapada" do Planalto dos Guimarães utilizarem manejos e estratégias considerados "modernos", assim como o plantio direto e a rotação de culturas, entre outros, sabe-se que as matas ciliares, que funcionam como "filtros" protetores naturais das margens e das nascentes das águas superficiais nessas áreas de produção, foram bastante suprimidas (SANTOS, 2002, 2005).

Nesse sentido, acredita-se que a realização de estudos que adotem uma abordagem que privilegie a compreensão da interação dos processos socioambientais entre estes dois ambientes (planalto e planície) é de suma importância para fornecer subsídios para a definição de políticas públicas que caminhem no sentido de um desenvolvimento sustentável para essa região.

Visto que a área da bacia vem sofrendo fortes consequências (supressão da vegetação, por exemplo) em função das ações antrópicas (MELLO; SANTOS, 2015), é necessário monitorar o ritmo da evolução dessas atividades sobre a área da bacia utilizando inclusive técnicas de sensoriamento remoto.
Dessa forma, tomando o uso e a ocupação do solo como agentes que possibilitam a identificação de processos e interações entre os dois ambientes geomorfológicos que compõem essa bacia, bem como o monitoramento das alterações ambientais decorrentes da ação antrópica na área, este estudo teve como objetivo principal o mapeamento da dinâmica das alterações do uso do solo e da cobertura vegetal na área da bacia do rio Mutum com utilização de imagens de sensoriamento remoto referente ao período das décadas de 1980, 1990, 2000 e 2010.

\section{O emprego do sensoriamento remoto na análise da cobertura vegetal e mapeamento do uso e ocupação do solo}

De acordo com Ferreira, Ferreira e Ferreira (2008), o sensoriamento remoto orbital apresentou grandes mudanças nos últimos trinta anos, assim como a vegetação do solo brasileiro. No estudo apresentam a evolução e o estado-da-arte dos sistemas de sensoriamento remoto, além das técnicas mais utilizadas para decodificar e classificar os valores espectrais da vegetação. Seu trabalho deixa claro que essa tecnologia se tornou indispensável para os estudos voltados à produção de análises da dinâmica espaço-temporal de uso e ocupação do solo em bacias hidrográficas.

Mascarenhas, Ferreira e Ferreira (2009) apresentam uma abordagem voltada para a análise da cobertura vegetal, por meio de sensoriamento remoto aplicado à bacia do rio Araguaia, com maior importância ao cerrado, o qual, para os autores, é um dos biomas que mais tem sofrido com o descaso da legislação ambiental. A região correspondente à bacia do Alto Araguaia, por exemplo, sofre com o desmatamento intenso desde 1970.

O desmatamento indiscriminado e intensivo, aliado a um novo sistema produtivo para a época (agropecuária), geraram como impactos o comprometimento da biodiversidade, o assoreamento e surgimento de processos erosivos e a contaminação dos solos e águas por fertilizantes e agrotóxicos (CASTRO, 2005 apud MASCARENHAS; FERREIRA; FERREIRA, 2008, p. 6).

Diante disso, o autor constatou que o sensoriamento remoto tem grande importância para o monitoramento dessas áreas a fim de verificar o cumprimento da legislação ambiental. $\mathrm{O}$ trabalho avaliou por meio de imagens de satélite sino-brasileiras CBERS-2 a cobertura vegetal remanescente na bacia do rio Araguaia, com maior 
importância às áreas de preservação permanente (APP) e constatou a conversão de $61 \%$ da vegetação da bacia.

Toebe (2009) também utilizou o sensoriamento remoto para realizar uma análise comparativa de imagens Landsat 5 no período de 1985 e 2008 a fim de quantificar as áreas com cobertura vegetal da bacia Sanga Sabiá nos municípios de Medianeira e Matelândia (PR). Seus resultados mostraram aumento de 25,54\% de cobertura vegetal (858,15 ha) de 1985 até 2008 devido à aplicabilidade da legislação ambiental e às áreas de reflorestamento.

Também dispondo de imagens do satélite Landsat 5 no período de 1984, 1994, 2004 e 2011 do município de Planaltina, de Goiás, Oliveira (2013) analisou a evolução do uso e da ocupação do solo dessa região, em que as imagens do período estudado foram classificadas e supervisionadas com auxílio de amostras para cada classe, as quais foram divididas em massa de água, vegetação alterada, agropecuária, vegetação natural e área urbana. Em 1985, os valores obtidos para cada classe foram: massa d'água - 0,09\%; vegetação alterada - 39,36\%; agropecuária - 15,54\%; vegetação natural - 44,28\%; e área urbana $-0,73 \%$. No último ano analisado, 2011 , os valores encontrados foram de, respectivamente, $0,17 \%$, $27,20 \%, 28,28 \%, 43,24 \%$ e $1,12 \%$. Sendo assim, as maiores alterações foram encontradas sobre a classe agropecuária e vegetação alterada.

Há, ainda, o trabalho de Santos e Santos (2010), que parte de técnicas de sensoriamento remoto e sistemas de informação geográfica (SIG) para mapear o uso do solo da região da bacia do rio Vaza-Barris, em Sergipe. As imagens adquiridas do satélite Spot 5 foram classificadas a partir da interpretação visual e delimitadas com um formato poligonal com o auxílio de fotografias aéreas do litoral sergipano. As classes foram produzidas com base no Manual técnico de uso da terra (IBGE, 2006). Dessa forma, foi possível destacar a ocupação predominante da classe pastagem com $64,29 \%$ na região de estudo. Essa característica é explicada como sendo a região de principal atividade rural, além dos solos pobres, os quais permitem que seja mais bem aproveitado para pastagens.

\section{Processos de transformação do uso e ocupação do solo em Mato Grosso e impactos na bacia do rio Mutum}

Até a década de 1980, Mato Grosso sofreu um forte processo de migração, como é apresentado por Cunha (2006), que destaca os impactos desse fenômeno na ocupação do solo do estado, bem como as principais consequências socioambientais desse processo.

Além disso, essa década também foi responsável por momentos de evolução tecnológica no que se trata de produção agrícola no Mato Grosso, provocando mudanças na composição e no manejo de lavouras (YOKOYAMA; IGREJA, 1992 apud DAL PAI; LIMA, 2012, p. 164).

França (2009), ao analisar as culturas agrícolas produzidas em Mato Grosso no período compreendido entre 1980 e 2007, objetivou relatar a proporção de lavouras na região e os problemas relacionados ao solo nesse mesmo período. $\mathrm{O}$ autor concluiu que a produção agrícola teve maior importância na produção voltada à exportação, que cresceu com o auxílio tecnológico, entretanto, o autor observou também indícios de impactos no uso do solo devido a essas atividades.

Quanto ao uso e ocupação do solo da área da bacia do rio Mutum, Mello e Santos (2015) buscaram mapear a região objetivando a determinação dos tipos de interferência antrópica no solo e as consequências ambientais dessa atividade. Seus resultados verificaram que a maior área de supressão da vegetação ocorre no setor planalto da bacia, principalmente pela produção agrícola, enquanto a planície da bacia apresentou uso predominante por pastagens divididas nos setores sul da bacia e norte sobre áreas da classe capoeira.

\section{Metodologia}

Buscou-se retratar neste estudo a dinâmica espaço-temporal do uso e da ocupação do solo da bacia do rio Mutum a partir da análise de quatro imagens orbitais (TM - ETM+/Landsat), sendo uma para cada década no período compreendido entre os períodos de 1980 e 2010 , todas referentes ao mês de maio, estação seca regional, época que essas imagens são menos prejudicas pela ocorrência de nuvens quando da passagem do satélite.

Em uma busca no banco de dados de imagens do Instituto Nacional de Pesquisas Espaciais (Inpe), foram verificadas as imagens com menores ruídos, como nuvens, correspondentes a cada década escolhida, de acordo com a Tabela 1 .

Após a aquisição das imagens, foram produzidas composições coloridas "falsa cor" (RGB) com elas, utilizando-se as bandas 5, 4, 3 nas imagens do período de 1985, 1995 e 2005, com as quais se verifica maior facilidade de identificação dos tipos de vegetação existentes na área da bacia. 
Tabela 1. Metadados das imagens orbitais.

\begin{tabular}{ccccc}
\hline Década & Satélite & Sensor & Cena/Óbita & Data de aquisição da imagem \\
\hline 1980 & Landsat5 & TM & $226 / 071$ & 16 de maio de 1985 \\
1990 & Landsat5 & TM & $226 / 071$ & 28 de maio de 1995 \\
2000 & Landsat5 & TM & $226 / 071$ & 07 de maio de 2005 \\
2010 & Landsat8 & ETM+ & $226 / 071$ & 13 de maio de 2014 \\
\hline
\end{tabular}

Fonte: Instituto Nacional de Pesquisas Espaciais (2015).

Posteriormente, essas três imagens foram corrigidas com os seguintes processos de pré-tratamento: correções geométricas com base no mosaico de imagens ortorretificadas GeoGover, normalização radiométrica (HALL et al., 1991) e correção atmosférica pelo método dark-object subtraction (DOS) proposto por Chavez Junior (1988).

Já a imagem do satélite Landsat 8, em 2014, passou primeiramente por um processo de "rescale", também chamado de conversão radiométrica, em que as bandas que compõem a imagem são todas convertidas de 16 para 8 bits. Após essa conversão, foi feita a composição colorida falsa cor (RGB), com as bandas 6, 5, 4, que gera um resultado semelhante ao obtido com a RGB 5, 4, 3 do sensor TM/Landsat 5. Também foi necessário uma reprojeção da imagem, pois as imagens Landsat 8 são orientadas para o norte verdadeiro. Isso quer dizer que, em vez de receber uma cena Landsat 8 na Projeção/ Datum WGS1984 UTM Zone 21S, recebemos uma cena Landsat 8 na Projeção/Datum WGS1984 UTM Zone $21 \mathrm{~N}$, sendo necessária, portanto, a sua reprojeção. A imagem de 2014 adquirida pelo satélite Landsat 8 já vem com correção geométrica (ortorretificada), com isso só foi necessário sua correção atmosférica, o que se deu pelo método DOS.

Depois do tratamento de todas as imagens, foi inserido sobre cada uma um arquivo em formato vetorial com o limite físico da bacia do rio Mutum, gerado e fornecido pelo Labgeo-UFMT/GUR, para que se pudesse ter a localização exata da área da bacia e, assim, realizar a classificação visual.

A classificação visual do uso e da ocupação do solo da bacia foi realizada empregando-se seis classes de uso e ocupação do solo para as diferentes datas, observando-se as orientações do Manual técnico de uso da terra (IBGE, 2006) para definição dessas classes, as quais foram: água (áreas cobertas por corpos de água), alagamento (áreas com processo de inundação e alagamento), floresta (vegetação de grande porte), lavoura (áreas destinadas à produção agrícola), savana (áreas cobertas vegetação de cerrado) e pastagem (áreas com capim destinadas à criação de gado). Logo após, visto que as imagens Landsat possuem resolução espacial de 30 x 30 m, foi necessário também o uso de uma imagem Spot 5 em 2007, de resolução espacial de 1 x 1 m, para que se obtivesse uma identificação mais precisa das classes. Desse modo, as classes de uso e ocupação do solo foram inicialmente identificadas sobre a imagem Landsat 8 de 2014 e as dúvidas sobre elas foram sanadas com o apoio da imagem Spot, identificadas e delimitadas a partir da comparação dessa imagem com a imagem de 2014, correspondente à década de 2010.

A partir da classificação da imagem desta década (2010), foi possível ter as chaves de interpretação para classificar as demais imagens das décadas anteriores. As classes de uso e ocupação do solo, contidas na área da bacia, interpretadas sobre a imagem foram delimitadas por polígonos vetoriais para que se pudesse calcular a área ocupada por cada uma na região estudada em cada data. A partir dos mapas e das quantificações das áreas ocupadas por cada classe em cada imagem, foi possível analisar a dinâmica de uso e ocupação do solo na bacia no período analisado.

\section{Resultados}

Levando em conta a área total da bacia de 341.032,67 ha, o setor de planalto ocupa uma área correspondente a 114.099 ha, com altitude média de 404 m, enquanto o setor da planície ocupa uma área de 226.933 ha (66\% da área da bacia), com altitude média de $167 \mathrm{~m}$.

\section{Uso e ocupação do solo da bacia na década de 1980}

A partir da análise da imagem de 1985, foi possível observar que a classe lavoura era responsável por cerca de apenas 8\% (25.861 ha) da área total da bacia; as lavouras se localizavam no setor leste, próximas ao limite da bacia. A classe pastagem era responsável por apenas 2\% (6.853 ha) ao norte. As demais classes, savana, floresta, água e área alagada, ocupavam $23 \%, 48 \%, 2 \%$ e 18\%, respectivamente, de acordo com a Figura 1. 


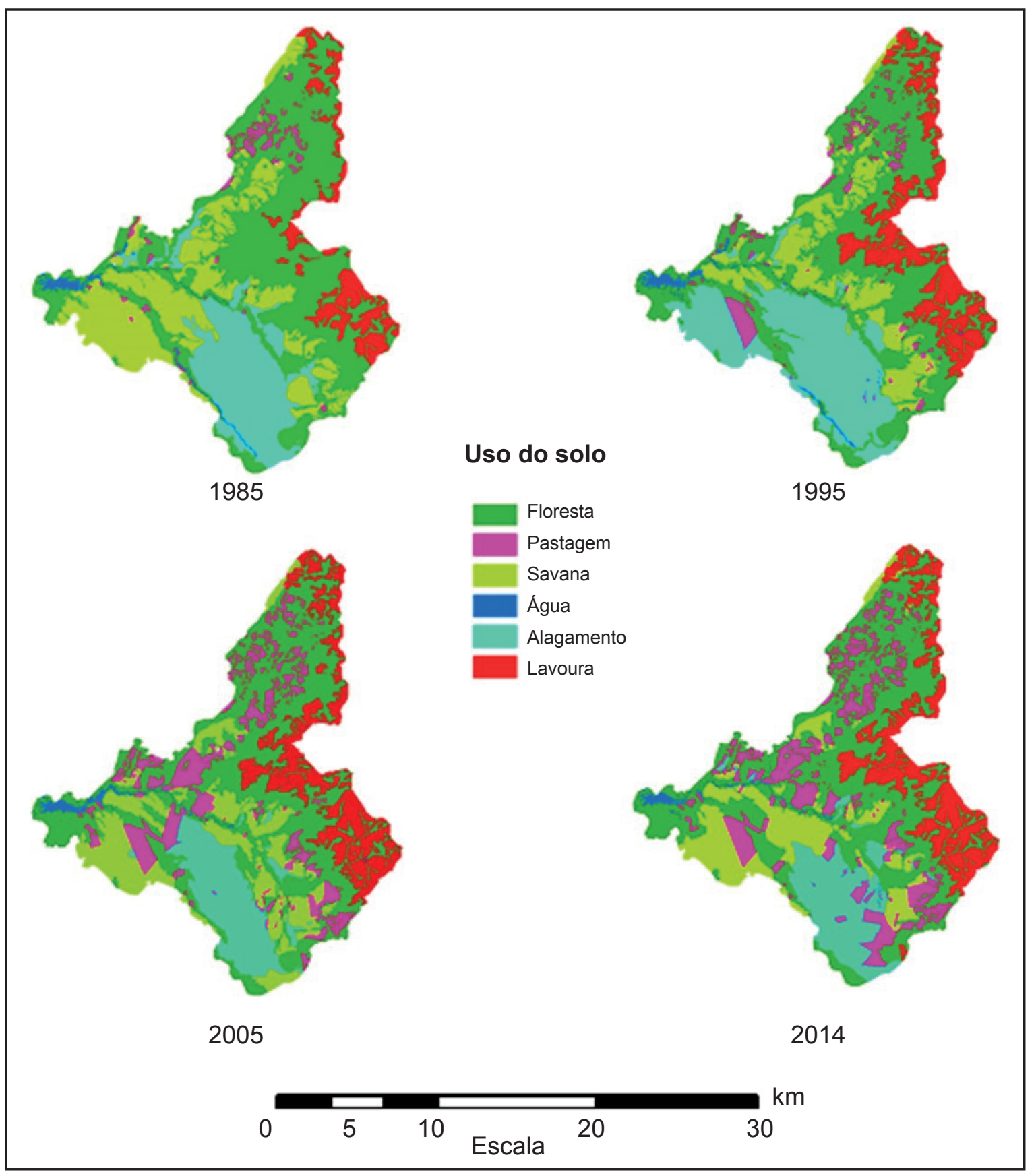

Figura 1. Evolução do uso e da ocupação do solo na bacia do rio Mutum no período de 1980 a 2010.

\section{Uso e ocupação do solo da bacia na década de 1990}

Na imagem correspondente ao período de 1995, foi possível detectar importantes avanços das áreas das classes pastagem e lavoura sobre a área de planície da bacia. A classe lavoura teve crescimento de apenas $5 \%$ (19.993 ha), mantendo-se no setor leste da bacia (terras de planalto). Já a classe pastagem se espalhou pelos setores sudeste e norte, principalmente em áreas da classe savana, que apresentou redução de $10 \%$, enquanto a pastagem dobrou de área, passando a ocupar 4\% (11.906 ha) da área total. (FIGURA 1).

\section{Uso e ocupação do solo da bacia na década de 2000}

A imagem do período de 2005 também revelou grande evolução da área ocupada pela classe pastagem. Enquanto a área da classe lavoura expandiu apenas 1\%, a da pastagem triplicou sua dimensão, passando a ocupar 12\% da área da bacia (38.567 ha), com presença marcante 
no centro-oeste da bacia e despontando também no setor norte dela, de acordo com a Figura 1.

\section{Uso e ocupação do solo da bacia na década de 2010}

Já na imagem do período de 2014, correspondente à década de 2010, demonstrou estabilidade no aumento da área da classe lavoura, permanecendo com área total de 14\% (48.384 ha), enquanto a área da classe pastagem continuou sua expansão em mais $2 \%$, totalizando uma ocupação de 47.548 ha, com detecção de novas áreas de pastagens no sul da bacia, mesmo sobre áreas classificadas como alagadas, de acordo com a Figura 1.

\section{Discussão dos resultados}

Os avanços da cultura agrícola sobre o cerrado de Mato Grosso ocorreram a partir da década de 1970 com a retomada de projetos de colonização pelo governo federal, sendo os principais ligados à produção de soja e algodão (MARTA; FIGUEIREDO, 2008) para fins de exportação. Foi também uma época em que a criação de gado teve avanço, assim como a produção de pastagens na área da bacia para esses fins, resultado do baixo custo de terras e mão de obra naquele período, além do clima propício da região.

Em 1980, a estrutura fundiária brasileira sofreu grandes alterações que elevaram a importância da área usada para o crescimento da economia, representada pelos avanços tecnológicos, que provocaram mudanças na formação das lavouras e pastagens, como a substituição de produtos agrícolas de menor custo por produtos de maior retorno (por exemplo: a soja) e substituição de pastagens naturais por artificiais. (YOKOYAMA; IGREJA, 1992 apud DAL PAI; LIMA, 2012, p. 164).

Em 1990, houve expansão das lavouras já existentes e surgimento de novas na região leste da bacia, despontando também áreas de lavouras no setor norte. Isso pode ter ocorrido devido ao incremento acentuado da participação da agropecuária na área fundiária do estado de Mato Grosso, consequente da mudança produtiva e tecnológica, ou ainda por uma progressiva conceituação da terra (CUNHA, 2006). Para a classe pastagem, foram observados uma pequena expansão e alguns focos espalhados no sudeste e sul da bacia. A mudança na proporção de pastagens pode ser explicada com dados do IBGE, que apontam crescimento de $80 \%$ da pecuária em toda a região de Mato Grosso no período compreendido de 1991 a 2000.
A imagem analisada da década de 2000 se encontra no período em que houve o salto da área ocupada por pastagens no estado de Mato Grosso. Hoffman et al. (2014) afirmam que em 1997 o estado se encontrava com 22,1 milhões de hectares, em 2006 passou a 25,8 milhões. Essa expansão notável também é observada na imagem classificada da região da bacia nessa mesma década. Quanto às lavouras, em 2006, Mato Grosso passou a ser considerado um dos principais estados agrícolas, sendo o maior produtor de soja e algodão e o segundo na produção de milho (IBGE, 2008). Essa evolução, porém, influenciou em apenas $1 \%$ no aumento dessa classe sobre a área da bacia, talvez em razão da maior parte da sua área se localizar na planície do pantanal, região sujeita a inundações sazonais.

Por último, a década de 2010 permaneceu praticamente estável, tanto no aumento de áreas de pastagens quanto no de lavouras. Acredita-se que esse fato seja resultado de pressões de instituições governamentais e ambientalistas contrários a aberturas de novas áreas produtivas agrícolas nessa área, fazendo que haja intensificação da produção pecuária, auxiliada por suplementação (HOFFMAN et al., 2014) e adoção de práticas de confinamento do gado. Algumas dessas práticas vêm sendo adotadas em substituição de pastagens por lavouras e/ou espaços destinados ao confinamento.

\section{Conclusão}

De acordo com os resultados alcançados no estudo, avalia-se que a técnica de interpretação visual de imagens orbitais se mostrou de grande eficiência na determinação das proporções das áreas ocupadas por cada classe mapeada, mesmo a despeito do elevado tempo para sua realização.

Já em relação à dinâmica do uso e da ocupação do solo da bacia, é possível concluir que a década de 1980 foi determinante no avanço de culturas agrícolas e pastoris na bacia, em consonância com o processo que ocorreu em todo o estado de Mato Grosso, devido ao baixo custo da terra e aos avanços nas técnicas de manejo do solo. Já no período compreendido entre 1995 e 2005, houve elevada expansão de pastagens sobre o estado de Mato Grosso, fato que também pode ser observado na bacia, principalmente pela imagem de 2005, resultado da alta demanda por produtos frigoríficos brasileiros para exportação. Já na última década analisada, observou-se que o processo de avanço das 
atividades agropecuárias sobre novas áreas da bacia diminuiu sensivelmente, tendendo a uma estabilidade, fato que pode estar relacionado à intensificação de ações de fiscalização na região por instituições governamentais e ambientais, fazendo-se necessária a adoção de novas medidas e práticas pelos pecuaristas e agricultores para ocupar novas áreas na bacia.

Por fim, considera-se que o estudo alcançou seu objetivo de caracterizar a dinâmica de uso e ocupação do solo na bacia do rio Mutum, revelando a situação atual da agricultura e, sobretudo, da pecuária, que, como se verificou, expandiu muito nos últimos anos no setor de planície da bacia, avançando até sobre áreas que ficam inundadas com frequência, enquanto as áreas de produção agrícola se restringiram à região de planalto das terras da bacia.

\section{REFERÊNCIAS}

CHAVEZ JUNIOR, P. S. An improved dark-object subtraction technique for atmospheric scattering correction of multispectral data. Remote Sensing of Environment, Flagstaff, v. 24, n. 3, p. 459-479, 1988. Disponível em: <http://bit.ly/2t3QsuI>. Acesso em: 26 jun. 2017.

CUNHA, J. M. P. Dinâmica migratória e o processo de ocupação do Centro-Oeste brasileiro: o caso de Mato Grosso. Revista Brasileira de Estudos de População, São Paulo, v. 23, n. 1, p. 87-107, jan./jun. 2006. Disponível em: <http://bit.ly/2tc6rq5>. Acesso em: 27 jul. 2015.

DAL PAI, C.; LIMA, J. F. Organização espacial e a evolução do uso de terras em Mato Grosso no final do século XX. Revista de Estudos Sociais, Guiabá, v. 14, n. 28, p. 149-167, 2012. Disponível em: <http://bit. ly/2sTHgGC>. Acesso em: 28 jul. 2015.

FERREIRA, L. G.; FERREIRA, N. G.; FERREIRA, M. E. Sensoriamento remoto da vegetação: evolução e estado-da-arte. Acta Scientiarum Biological Sciences, Maringá, v. 30, n. 4, p. 379-390, 2008. Disponível em: <http://bit.ly/2tesVHG>. Acesso em: 8 abr. 2015.

FRANÇA, M. T. Análise do crescimento do volume da produção agrícola na região norte mato-grossense e sua relação com os problemas de solo no período de 1980 a 2007. 2009. 121 f.
Dissertação (Mestrado em Ciências Econômicas) Faculdade de Economia, Universidade Federal de Mato Grosso, Cuiabá, 2009.

HOFFMANN, A. et al. Produção de bovinos de corte no sistema de pasto-suplemento no período seco. Nativa, Sinop, v. 2, n. 2, p. 119-130, abr./jun. 2014. Disponível em: <http://bit.ly/2tdtrW3>. Acesso em: 26 jun. 2017.

INSTITUTO BRASILEIRO DE GEOGRAFIA E ESTATÍSTICA - IBGE. Manual técnico de uso da terra. 2. ed. Rio de Janeiro: IBGE, 2006.

MARTA, J. M. C.; FIGUEIREDO, A. M. R. Expansão da soja no cerrado de Mato Grosso: aspectos políticos. Revista de Política Agrícola, Brasília, DF, v. 17, n. 1, p. 108-116, 2008. Disponível em: < http://bit.ly/2sJvBLR>. Acesso em: 26 jun. 2017.

MASCARENHAS, L. M. A.; FERREIRA, M. E.; FERREIRA, L. G. Sensoriamento remoto como instrumento de controle e proteção ambiental: análise da cobertura vegetal remanescente na bacia do Rio Araguaia. Sociedade \& Natureza, Uberlândia, v. 21, n. 1, p. 5-18, 2009. Disponível em: <http://bit.ly/2seE725>. Acesso em: 26 jun. 2017.

MeLlO, A. P. G.; SANTOS, J. W. M. C. Análise da variação temporo-espacial da qualidade das águas da Lagoa Sinhá Mariana, Pantanal Norte Mato-grossense, a partir de Imagens MODIS em coletas in loco. In: SIMPÓSIO BRASILEIRO DE SENSORIAMENTO REMOTO, 17., 2015, João Pessoa. Anais... São José dos Campos: Inpe, 2015. p. 6110-6118. Disponível em: <http://bit.ly/2sa7LdI>. Acesso em 26 jun. 2017.

NASCIMENTO, M. C. et al. Mapeamento dos fragmentos de vegetação florestal nativa da bacia hidrográfica do rio Alegre, Espirito Santo, a partir de imagens do satélite IKONOS II. Revista Árvore, Viçosa, v. 30, n. 3, p. 389-398, maio/jun. 2006. Disponível em: <http:// bit.ly/2rUUmls>. Acesso em: 28 jul. 2015.

OLIVEIRA, E. S. Estudo preliminar sobre a evolução do uso e ocupação do solo no município de Planaltina de Goiás. Revista Geotemas, Pau dos Ferros, v. 3, n. 1, p. 111-123, jan./jun. 2013. Disponível em: <http:// bit.ly/2u9tK0P>. Acesso em: 26 jun. 2017. 
SANTOS, A. L. G.; SANTOS, F. Mapeamento das classes de uso e cobertura do solo da bacia hidrográfica do rio Vaza-Barris, Sergipe. Saber Acadêmico, São Paulo, n. 10, p. 57-67, dez. 2010. Disponível em: <http://bit. ly/2teyg $1 \mathrm{~J}>$. Acesso em 26 jun. 2017.

\section{SANTOS, J. W. M. G. Clima e produtividade da soja} nas terras de cerrado do sudeste de Mato Grosso. 2002. 388 p. Tese (Doutorado em Geografia Física) Faculdade de Filosofia, Letras e Ciências Humanas, Universidade de São Paulo, São Paulo, 2002.
Ritmo climático e sustentabilidade sócio-ambiental da agricultura comercial da soja no sudeste de Mato Grosso. Revista do Departamento de Geografia, São Paulo, n. 17, p. 61-82, 2005.

TOEBE, D. Análise comparativa da cobertura florestal utilizando técnicas de sensoriamento remoto na bacia Sanga Sabiá nos anos de 1985 e 2008. 2009. 70 f. Trabalho de Conclusão de Curso (Bacharelado em Engenharia Ambiental) - União Dinâmica de Faculdades Cataratas, Foz do Iguaçu, 2009. 